\title{
Road traffic fatalities in Qatar, Jordan and the UAE: estimates using regression analysis and the relationship with economic growth
}

A. Bener, ${ }^{7}$ S.J. Hussain, ${ }^{2}$ M.A. Al-Malki, ${ }^{3}$ M.M. Shotar, ${ }^{4}$ M.F. Al-Said ${ }^{5}$ and K.S. Jadaan ${ }^{6}$

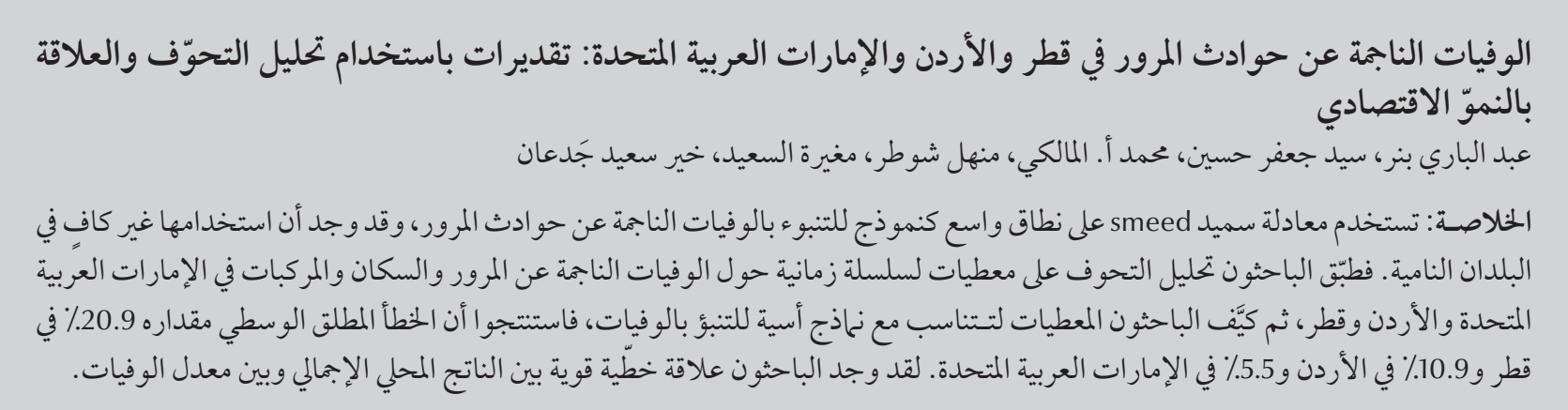

ABSTRACT Smeed's equation is a widely used model for prediction of traffic fatalities but has been found inadequate for use in developing countries. We applied regression analysis to time-series data on vehicles, population and traffic fatalities in the United Arab Emirates (UAE), Jordan and Qatar. The data were fitted to exponential models for fatality prediction, producing an average absolute error of 20.9\% for Qatar, $10.9 \%$ for Jordan and 5.5\% for the UAE. We found a strong linear relationship between gross domestic product and fatality rate.

Décès par accidents de la circulation au Qatar, en Jordanie et aux Émirats arabes unis : estimation à l'aide de I'analyse de régression et relation avec la croissance économique

RÉSUMÉ L'équation de Smeed est un outil très courant pour prévoir les décès par accident de la circulation, mais s'est révélée inadaptée pour les pays en développement. Nous avons appliqué une analyse de régression aux données de série chronologique des véhicules, de la population et des décès par accident de la circulation aux Émirats arabes unis (EAU), en Jordanie et au Qatar. Les données ont été adaptées aux modèles exponentiels pour les prédictions relatives à la mortalité, générant une erreur moyenne absolue de 20,9\% pour le Qatar, de 10,9\% pour la Jordanie et de 5,5\% pour les EAU. Une forte relation linéaire entre le produit intérieur brut et le taux de mortalité a été observée.

'Department of Public Health, Weill Cornell Medical College of Qatar, Doha, Qatar (Correspondence to A. Bener:abener@hmc.org.qa; abaribener@hotmail.com).

${ }^{2}$ Healthy Lifestyle Promotion, Violence and Injury Prevention, World Health Organization Regional Office for the Eastern Mediterranean, Cairo, Egypt.

${ }^{3}$ General Administration of Public Security, Traffic and Patrol Department, Ministry of Interior, Doha, Qatar.

${ }^{4}$ Department of Finance and Economics, College of Business and Economics, University of Qatar, Doha, Qatar.

${ }^{5}$ National Health Authority, Doha, Qatar.

${ }^{6}$ Department of Civil Engineering, Faculty of Engineering, Al-Isra Private University, Amman, Jordan.

Received: 12/07/07; accepted: 21/11/07 


\section{Introduction}

According to a World Health Organization $(\mathrm{WHO})$ report, it is estimated that 5.8 million deaths are due to injuries, making this the third leading cause of death in the world [1]. Road traffic accidents are a major cause of all injuries and are known to be a factor in the majority of deaths, hence making road traffic injuries (RTIs) the 9th leading cause of disability adjusted life years (DALYs) lost worldwide [2]. Road traffic fatality rates of a country are known to depend upon factors such as population, the number of motor vehicles in use, the total length of roads, the population density and economic conditions $[3,4]$. With over 1 million killed in car crashes annually, traffic injuries are projected to become the 3rd leading cause of DALYs lost by 2020 [5]. In general, the total costs of road crashes and fatalities are a burden for the country and costs vary from $2.8 \%$ to $5 \%$ of the gross national product $[6,7]$. Among developed countries, each year there are up to 500000 deaths and 15 million injuries worldwide as a result of road traffic crashes. This represents 1400 fatalities and 41000 injuries per day, and a quarter of these are in the most highly developed countries [8].

Smeed devised a formula that estimates the road traffic fatalities of a country by using the population and the number of registered vehicles of that country $[9,10]$. Later, Andreassen said that Smeed looked at deaths per vehicle plotted against vehicles per capita and argued that the relationship found between these variables was not valid, but did help to put crash rates into perspective [11]. Referring to Smeed's equation, Haight reported that when the formula disagrees with observations, certain authors tended to assume that the particular area under investigation was "safer" or "less safe" than it "ought to be" [12]. Hampson used Smeed's equation to estimate the number of traffic fatalities in New South Wales,
Australia over a period of 20 years [13]. The observed fatalities were on average $20 \%$ higher than estimated.

It has long been known that annual motor vehicle deaths vary in a similar pattern to economic activity [7]. A biphasic relationship between traffic fatalities and economic development has been recorded, with fatalities rising for the low income countries and falling for the high income countries [14]. Several cross-sectional studies have been performed to identify the association between economic growth and traffic fatalities: the results were more or less contradictory. A World Bank study showed that the economic development of regions and nations is associated with an increase in the number of injuries and deaths from road traffic crashes [15]. Increased road safety is related to socioeconomic development [1]. These studies show that no uniform relationship can be derived between prosperity and road traffic crash mortality.

Qatar experienced a rapid transition in socioeconomic status after the discovery of oil in the mid 1990s, with a dramatic rise in the national economy, expressed in terms of per capita income: the gross domestic product (GDP) per capita was estimated at US\$ 67000 in 2007 [16]. This has led to road crashes and the resulting fatalities being regarded as a growing social and economic problem in Qatar.

It has been predicted that traffic fatalities will be the 6th leading cause of death worldwide and the 2nd leading cause of DALYs lost in developing countries by the year 2020 [5]. The effects of some of the contributing factors on traffic fatalities have been studied and correlations to predict fatalities were developed $[6,12,15,17-19]$. However, these produced quite large deviations between the expected and the observed fatalities.

The objective of this study was to estimate road traffic fatalities using regression analysis and to compare the results with those derived using Smeed's equation for estimating fatalities. Additionally, we aimed to identify the relationship between economic growth and traffic fatalities and to test the model using the statistics available from the United Arab Emirates (UAE), Jordan and Qatar.

\section{Methods}

We collected the data on vehicles registered and fatalities from the traffic department and the population estimate and GDP from the Annual Health Report [20] of Hamad Medical Corporation and the Directorate of Traffic, Ministry of the Interior, Qatar for the period 1990-2006.

\section{Applications of Smeed's equation}

International comparisons of road safety can be very misleading and one of the difficulties in this field was deciding on the rate to be used so that population size and number of motor vehicles in a country would not contaminate the comparisons. To overcome this difficulty, Smeed used data for road fatalities, vehicles and population for the year 1938 from 20 countries (the majority of which were European) to derive a rather complicated relationship which is expressed by the formula [9]:

$$
D / V=0.0003(V / P)^{-0.67}
$$

where $D=$ number of road fatalities, $V=$ number of vehicles and $P=$ population.

Smeed's Law is an empirical rule relating traffic fatalities to motor vehicle registrations and country population. Thus annually increasing traffic volume leads to a decrease in crashes per vehicle. It was posited after an analysis of figures from a number of countries over several decades.

Smeed's formula is expressed as:

$$
D=0.0003\left(n p^{2}\right)^{1 / 3}
$$


or, weighted per capita:

$$
D / p=0.0003 \times \sqrt[3]{ }(n / p)
$$

where $D$ is annual road deaths, $n$ is number of registered vehicles, and $p$ is population. Smeed showed this relationship worked for 20 different countries. However, the validity of the formula has also been disputed by several authors $[11,19,21,22]$. Smeed showed that, although originally derived from data for 1938, this formula was equally applicable to data from 1960-67 or even later [10]. Further support for the formula came from Preston [23] who carried out a comparison of fatalities reported in 1977 for 32 countries (developed and developing) and the expected fatalities as calculated by Smeed's formula. Despite a percentage deviation of the expected road fatalities from the observed ranged between $-83 \%$ and 191\%, Preston concluded that Smeed's formula was still applicable and fitted data for 1977, which lends credence to his suggestion that it represents a consensus of the level of road fatalities that countries are prepared to tolerate.

Using methods similar to those used by Smeed, an analysis of fatality rates in developing countries was carried out by Jacobs and Bardsley [24] in 1977 for 32 developing countries; the fatalities per 10000 persons and the number of fatalities per 10000 vehicles were calculated and compared. The relationship is expressed by the equation:

$$
D / V=0.000742(V / P)^{-0.43}
$$

which is statistically significant at the $1.0 \%$ level.

In order to see whether this relationship was stable over time, the analysis was repeated using 1971 data [24] producing the following relationship:

$$
D / V=0.000914(V / P)^{-0.43}
$$

For the same level of vehicle ownership, the equation for 1971 gives a 24\% increase in fatality rate over the 1968 equation.
Using regression analysis and data from Qatar for the period 1990-2004 [22], a Smeed-type formula of the following form, which is statistically significant at the 95\% level, was derived:

$$
D / V=0.0004079(V / P)^{\mathrm{t}}
$$

Where $t$ refers to $95 \%$ CI $(-0.746$ to $-0.254)$.

The constants were restrained to be the same for comparison purposes.

Bener and Ofosu [19] repeated the analysis done by Smeed for Saudi Arabia, and the following relationship was derived:

$$
D / V=0.00021(V / P)^{-0.72} .
$$

\section{Recent fatality prediction models}

The universality of the above model by Smeed was tested on a number of occasions. Cross-sectional data for 32 countries showed that on average the expected fatalities as estimated by Smeed's formula exceeded the observed by $21 \%$ [23]. When applied to time-series data over 20 years for New South Wales, fatalities predicted using Smeed's formula were on average $20 \%$ lower than observed [13]. Smeed's formula has therefore been subject to recent criticism.

Given the relatively large deviations between observed and expected values Andreassen reported "Smeed's law has proved to be an imperfect predictive tool," then concluded that the formula "cannot be extended to predict the number of fatalities in any year in any country" and "the equation $\mathrm{D}=$ constant. (p)BI (V) B2 is poor" [11]. He also concluded that Smeed's equation was not suitable for the estimation of number of fatalities as it produces biased estimates which are very sensitive to small variations in data.

The above points are well understood since the variation in a number of countries is not accounted for by the use of only population and number of vehicles. A universal model that can be used for international comparison should, therefore, incorporate other relevant variables.

\section{Development of fatality prediction models}

Smeed's law has a plenty of critics who usually concentrate on the fact that the number of vehicles ( $\mathrm{V}$ ) appears on both sides of the equation and that there is considerable deviation between the expected and actual number of road fatalities. The latter is clearer when the equation is applied to developing countries. In addition, the above review indicates that different countries might need different constants in the Smeed equation, a conclusion suggested by Andreassen [11], Bener and Ofosu [19], and Jadaan, Khalil and Bener [22] and demonstrated in the results of our study. These points indicated that a new predictive model for road fatalities needs to be developed which fits the data of developing countries and provides better estimates than Smeed's equation.

\section{Results}

Time-series data of road fatalities, vehicles and population for Qatar, UAE and Jordan are shown in Tables 1,2 and 3. It was believed that the data could be fitted successfully to a regression model. Two models were developed using regression analysis (least squares method) and tested. These models had the following forms:

\section{Model 1}

$$
D=299.449 \ln (V)-249.095 \ln (P)
$$

or

$$
\begin{gathered}
D=\ln \left(V^{299.449} \cdot p^{-249.095}\right) \\
R^{2}=0.801
\end{gathered}
$$

\section{Model 2}

$$
\begin{gathered}
D=1311.872+384.502 \ln (V)- \\
420.486(P)
\end{gathered}
$$

or 


\begin{tabular}{|c|c|c|c|c|c|c|c|}
\hline \multirow[t]{2}{*}{ Year } & \multirow[t]{2}{*}{ Vehicles } & \multirow[t]{2}{*}{ Population } & \multicolumn{3}{|c|}{ Fatalities } & \multicolumn{2}{|c|}{ Error (\%) } \\
\hline & & & $A \|^{a}$ & $\begin{array}{c}\text { Regression } \\
\text { analysis estimate }\end{array}$ & $\begin{array}{l}\text { Smeed's } \\
\text { equation } \\
\text { estimate }\end{array}$ & $\begin{array}{l}\text { Regression } \\
\text { analysis }\end{array}$ & $\begin{array}{l}\text { Smeed's } \\
\text { equation }\end{array}$ \\
\hline 1990 & 303284 & 1844300 & 394 & 450 & 303 & 14.3 & 23.1 \\
\hline 1991 & 309539 & 1908800 & 490 & 454 & 312 & -7.3 & 36.3 \\
\hline 1992 & 344850 & 2011400 & 510 & 486 & 335 & -4.6 & 34.3 \\
\hline 1993 & 398788 & 2083100 & 567 & 539 & 360 & -5.0 & 36.5 \\
\hline 1994 & 428149 & 2230000 & 600 & 563 & 386 & -6.2 & 35.7 \\
\hline 1995 & 437945 & 2377453 & 563 & 568 & 406 & 0.8 & 27.9 \\
\hline 1996 & 442700 & 2477899 & 492 & 569 & 419 & 15.6 & 14.9 \\
\hline 1997 & 468440 & 2624000 & 619 & 590 & 443 & -4.7 & 28.4 \\
\hline 1998 & 539407 & 2759000 & 646 & 657 & 480 & 1.7 & 25.6 \\
\hline 1999 & 557668 & 2938000 & 624 & 669 & 507 & 7.2 & 18.8 \\
\hline 2000 & 575929 & 3108000 & 673 & 682 & 532 & 1.3 & 21.0 \\
\hline 2001 & 605696 & 3290000 & 733 & 705 & 561 & -3.8 & 23.4 \\
\hline 2002 & 633817 & 3754000 & 743 & 717 & 622 & -3.5 & 16.2 \\
\hline 2003 & 661937 & 4041000 & 756 & 736 & 663 & -2.7 & 12.3 \\
\hline 2004 & 690058 & 4320000 & 729 & 754 & 703 & 3.5 & 3.5 \\
\hline
\end{tabular}

${ }^{a}$ Total deaths reported to the Road Traffic Authority.

$$
\begin{gathered}
D=\ln \left(\mathrm{e}^{1311.872} \cdot V^{384.502} \cdot p^{-420.486}\right) \\
R^{2}=0.840
\end{gathered}
$$

where $V, D$ and $P$ are as above.

The regression output shows that all the models (Tables $1-3$ ) are statistically significant, indicating that more than $80 \%$ of the road fatalities in Qatar, the UAE and Jordan can be explained by population and the number of vehicles. Comparing the actual and predicted number of fatalities, all the models gave better estimates than Smeed's equation. The average absolute percentage errors were $23.9 \%$ and $29.6 \%$ for Smeed's equation for the UAE and Qatar respectively. The corresponding figure for Jordan, the

\begin{tabular}{|c|c|c|c|c|c|c|c|}
\hline \multirow[t]{2}{*}{ Year } & \multirow[t]{2}{*}{ Vehicles } & \multirow[t]{2}{*}{ Population } & \multicolumn{3}{|c|}{ Fatalities } & \multicolumn{2}{|c|}{ Error (\%) } \\
\hline & & & All & $\begin{array}{c}\text { Regression } \\
\text { analysis estimate }\end{array}$ & $\begin{array}{l}\text { Smeed's } \\
\text { equation } \\
\text { estimate }\end{array}$ & $\begin{array}{l}\text { Regression } \\
\text { analysis }\end{array}$ & $\begin{array}{l}\text { Smeed's } \\
\text { equation }\end{array}$ \\
\hline 1990 & 254617 & 3453000 & 379 & 345 & 434 & -12.4 & -10.3 \\
\hline 1991 & 259196 & 3888000 & 379 & 398 & 473 & -18.7 & 3.5 \\
\hline 1992 & 276301 & 4012000 & 388 & 426 & 493 & -16.5 & 3.3 \\
\hline 1993 & 291347 & 4152000 & 440 & 453 & 514 & -20.1 & 9.4 \\
\hline 1994 & 304893 & 4200000 & 443 & 469 & 526 & -21.9 & 12.4 \\
\hline 1995 & 321373 & 4290100 & 469 & 492 & 543 & -12.7 & 3.6 \\
\hline 1996 & 342337 & 4444000 & 552 & 525 & 567 & 6.8 & -15.3 \\
\hline 1997 & 362811 & 4600000 & 577 & 559 & 592 & -9.8 & 4.4 \\
\hline 1998 & 389196 & 4755800 & 612 & 596 & 619 & -7.7 & 4.1 \\
\hline 1999 & 418433 & 4900000 & 676 & 635 & 647 & 1.8 & -3.7 \\
\hline 2000 & 473339 & 5039000 & 686 & 693 & 687 & 2.9 & -2.1 \\
\hline 2001 & 509832 & 5182000 & 783 & 737 & 718 & 0.5 & 2.1 \\
\hline 2002 & 542812 & 5329000 & 758 & 779 & 747 & 4.8 & -0.5 \\
\hline 2003 & 571498 & 5480000 & 832 & 818 & 774 & 8.1 & -2.4 \\
\hline 2004 & 612330 & 5650000 & 818 & 868 & 808 & 19.1 & -10.9 \\
\hline
\end{tabular}
population of which is very much larger 


\begin{tabular}{|c|c|c|c|c|c|c|c|}
\hline \multirow[t]{2}{*}{ Year } & \multirow[t]{2}{*}{ Vehicles } & \multirow[t]{2}{*}{ Population } & \multicolumn{3}{|c|}{ Fatalities } & \multicolumn{2}{|c|}{ Error (\%) } \\
\hline & & & All & $\begin{array}{c}\text { Regression } \\
\text { analysis } \\
\text { estimate }\end{array}$ & $\begin{array}{l}\text { Smeed's } \\
\text { equation } \\
\text { estimate }\end{array}$ & $\begin{array}{l}\text { Regression } \\
\text { analysis }\end{array}$ & $\begin{array}{l}\text { Smeed's } \\
\text { equation }\end{array}$ \\
\hline 1990 & 161262 & 422145 & 96 & 63 & 92 & -34.4 & 4.3 \\
\hline 1991 & 177082 & 435658 & 96 & 70 & 97 & -27.1 & -0.8 \\
\hline 1992 & 190050 & 449606 & 116 & 76 & 101 & -34.5 & 12.7 \\
\hline 1993 & 203001 & 464009 & 84 & 81 & 106 & -3.6 & -25.8 \\
\hline 1994 & 207912 & 476402 & 52 & 84 & 108 & 61.5 & -108.5 \\
\hline 1995 & 217802 & 494225 & 99 & 88 & 113 & -11.1 & -14.0 \\
\hline 1996 & 231006 & 510070 & 89 & 94 & 118 & 5.6 & -32.0 \\
\hline 1997 & 249787 & 526429 & 96 & 102 & 123 & 6.3 & -28.3 \\
\hline 1998 & 269510 & 543315 & 106 & 111 & 129 & 4.7 & -21.7 \\
\hline 1999 & 284018 & 560746 & 96 & 118 & 134 & 22.9 & -39.7 \\
\hline 2000 & 299611 & 578470 & 85 & 124 & 139 & 45.9 & -64.0 \\
\hline 2001 & 319318 & 595321 & 110 & 133 & 145 & 20.9 & -31.9 \\
\hline 2002 & 348840 & 616151 & 114 & 146 & 153 & 28.1 & -34.1 \\
\hline 2003 & 366532 & 717984 & 150 & 154 & 172 & 2.7 & -14.8 \\
\hline 2004 & 402006 & 755163 & 164 & 170 & 184 & 3.7 & -12.0 \\
\hline 2005 & 457239 & 796186 & 206 & 181 & 199 & -12.1 & 3.6 \\
\hline 2006 & 544013 & 837209 & 270 & 233 & 218 & -13.7 & 19.4 \\
\hline
\end{tabular}

than the populations of of the UAE and Qatar, was 5.8\% (Table 4).

\section{Discussion}

The results obtained in our study are consistent with other reported studies $[6,12,15,17-19]$ that equation (2) applies to both industrialized and developing countries, although with different values of $\alpha$ and $\beta$, safety and hazard indices, respectively, of a country [19].

Also, the ratio of deaths per vehicle should not be used as a measure for international comparisons because deaths are generally non-linearly related to vehicles.
It has been reported that high per capita economic growth in a country is no longer associated with additional traffic deaths $[17,18]$, although the vehicle population and number of crashes increase with economic growth. We identified a different trend in Qatar which deviates from this image. Although the GDP per capita in Qatar was US\$ 62700 in 2006, fatalities increased with economic growth. This positive association between GDP and traffic deaths in Qatar may be due to the lack of improvement in the traffic infrastructure and availability of improved trauma care. Improvements in pre-hospital and emergency medical care could reduce death rates.

\begin{tabular}{lcc}
\hline $\begin{array}{l}\text { Table } 4 \text { Comparison of average absolute error for Smeed's equation and } \\
\text { regression equation }\end{array}$ & \multicolumn{2}{c}{ Average absolute error } \\
\hline Country & Smeed's equation & Regression equation \\
& 23.9 & 5.5 \\
United Arab Emirates & 5.8 & 10.9 \\
Jordan & 29.6 & 20.9 \\
Qatar & &
\end{tabular}

It has been indicated in a few individual countries that increased prosperity in itself is not sufficient to reduce the number of traffic deaths. A major public health challenge is to utilize this experience to avoid the predicted increase in traffic-related mortality in less-developed countries [25]. For example, in Spain and Greece, the traffic crash mortality rate continued to rise after passing the prosperity level that is expected to become protective. Both countries have so far been less successful in reducing their fatal injury rates than most other countries. This indicates that, regardless of the level of economic development, active policies and trauma care to reduce the number of traffic deaths should never be neglected.

\section{Conclusion}

Regression analysis can be applied to estimate road fatalities in Qatar although adjustment of bias is one of the weaknesses. Applying Smeed's equation to the data for Qatar produced a much 
greater error than that produced by regression analysis. Smeed's equation cannotbe extended to accurately predict the number of deaths in any year in any country. Smeed's equation calculation results in a considerable deviation of the actual road fatalities from the expected number in developing countries.

\section{References}

1. World health report 2001: Mental health: new understanding, new hope. Geneva, World Health Organization, 2001.

2. Peden $\mathrm{M}$ et al. World report on road traffic injury prevention. Geneva, World Health Organization, 2004.

3. Bener A, Crundall D. Road traffic accidents in the United Arab Emirates compared to western countries. Advances in transport studies, 2005, 6:5-12.

4. Paulozzi LJ et al. Economic development's effect on road transport-related mortality among different types of road users: a cross-sectional international study. Accident analysis \& prevention, 2007, 39:606-17.

5. Murray C, Lopez A, eds. The global burden of disease. Cambridge, Massachusetts, Harvard Press, 1996.

6. Elvik R. Analysis of official economic valuations of traffic accident fatalities in 20 motorized countries. Accident analysis \& prevention, 1995, 27:237-47.

7. Bener $\mathrm{A}$ et al. Strategy to improve road safety in developing countries. Saudi medical journal, 2003, 24:603-8.

8. Hasson P. Rural road safety: a global challenge. Public roads, 1999 63(2) (http://www.tfhrc.gov/pubrds/septoct99/ruralrds.htm, accessed 2 August 2009).

9. Smeed RJ. Some statistical aspects of road safety research. Journal of the Royal Statistical Society, Series-A, 1949, 12:1-23.

10. Smeed RJ. Methods available to reduce the number of road casualties. Traffic engineering \& control, 1964, 6:509-12.

11. Andreassen DC. Linking deaths with vehicles and population. Traffic engineering \& control, 1985, 26:547-9.

12. Haight FA. Traffic safety in developing countries. Journal of safety research, 1980, 12:50-8.

13. Hampson G. The theory of accident compensation and the introduction of compulsory seat belt legislation in New South Wales. Proceedings of the Australian Road Research Board Conference, 1982, 11:135-40.
14. Van Beeck EF, Borshoom GJ, Mackenbach JP. Economic development and traffic accident mortality in the industrialised world, 1962-1990. International journal of epidemiology, 2000, 29:503-9.

15. Kopits E, Cropper MI. Traffic fatalities and economic growth. Washington DC, World Bank, 2003 (Policy Research Working Paper 3035).

16. About Qatar. Doha, Bureau of Public Affairs, 2009 (http:// www.state.gov/r/pa/ei/bgn/5437.htm, accessed 29 July 2009).

17. Bishai D. Traffic fatalities and economic growth. Accident analysis \& prevention, 2005, 37:169-78.

18. Bishai $D$ et al. National road casualties and economic development. Health economy, 2006, 15:65-81.

19. Bener A, Ofosu JB. Road traffic fatalities in Saudi Arabia. Journal of the International Association of Traffic and Safety Sciences, 1991, 15:35-8.

20. Annual health report. Doha, Qatar, Hamad Medical Corporation, 2006.

21. Global economic prospects 2002: making trade work for the world's poor. Washington DC, World Bank, 2002 (http://publications.worldbank.org/ecommerce/catalog/product?item id=432634, accessed 29 July 2009).

22. Jadaan KS, Khalil R, Bener A. A mathematical model using convex combination for the prediction of road traffic deaths. Journal of computing \& information, 1991, 2:139-57.

23. Preston B. Road safety: international comparisons. Transport reviews, 1980, 1:75-98.

24. Jacobs, GD, Bardsley MN. Research on road accidents in developing countries", Traffic engineering \& control, 1977, 18:166-70.

25. Soderlund N, Zwi AB. Traffic-related mortality in industrialized and less developed countries. Bulletin of the World Health Organization, 1995, 73:175-82. 